Griffith Edwards has rightly observed that alongside our declared medical approach to drug dependence is a penal response to the problem-to a considerable but hidden extent. Both the size and the desirability of this development need examination and debate.

${ }^{1}$ Ministry of Health, Report of the Departmental Committee on Morphine and Heroin Addiction. London, HMSO, 1926.

2 Spear, H B, British Fournal of Addiction, 1969/70, 64, 245

${ }^{3}$ Bewley, T H, Bulletin on Narcotics, 1966, 18, 1.

4 d'Orbán, P T, The Practitioner, 1974, 212, 823.

${ }^{5}$ Dole, V P, and Nyswander, M, fournal of the American Medical Association, 1965, 193, 646.

${ }^{6}$ Wiepert, G D, Bewley, T H, and d'Orbán, P T, Bulletin on Narcotics, $1978,30,21$.

7 Stimson, G V, Oppenheimer, E, and Thorley, A, British Medical fournal, $1978,1,1190$.

8 Blumberg, H H, British fournal of Addiction, 1976, 71, 65

Bewley, T H, et al, fournal of the Royal College of General Practitioners, $1975,25,654$

10 Aylett, P, British fournal of Addiction, 1978, 73, 385

11 Wiepert, G D, d'Orbán, P T, and Bewley, T H, British fournal of Psychiatry, 1979, 134, 14.

12 Edwards, G, British fournal of Psychiatry, 1979, 134, 1.

${ }^{13}$ Mitcheson, M, and Hartnoll, R, in Problems of Drug Abuse in Britain, ed D J West, p 74. Cambridge, Institute of Criminology, 1978.

14 Blumberg, H H, and Dronfield, B E, Social Science and Medicine, 1976, $10,415$.

15 Blumberg, H H, et al, International fournal of the Addictions, 1974, 9, 1.

${ }_{16}$ Smart, R G, and Ogborne, A, British fournal of Addiction, 1974, 69, 225.

17 Ghodse, A H, British Medical fournal, 1977, 1, 1381.

18 Advisory Council on the Misuse of Drugs, First Interim Report. London, DHSS, 1977.

19 Guide to the Misuse of Drugs Act 1971 and to Certain Regulations Made Under the Act. London, DHSS, 1977.

${ }^{20}$ d'Orbán, P T, Fournal of Medical Ethics, 1976, 2, 63.

${ }^{21}$ Ghodse, A H, British Fournal of Psychiatry, 1977, 131, 273.

\section{Yaws or syphilis?}

Yaws occurs in those parts of the world between the tropics of Cancer and Capricorn, especially in the hot, humid environment of rain forests. It is found in some of the Caribbean islands and in West Africa, areas which have sent many immigrants to Britain. Active yaws is rarely seen in immigrants, though there have been isolated reports of early yaws in newly arrived immigrant children and of late bone lesions in adults. ${ }^{1-5}$ The most common mode of presentation is a latent infection brought to light by routine serological tests for syphilis. In the first half of 1976 no fewer than 540 new patients attending venereal disease clinics in England were diagnosed as having "other treponemal disease" compared with 1860 with acquired syphilis, ${ }^{6}$ so that imported yaws is not rare. The increasing use of sensitive screening procedures such as the Treponema pallidum haemagglutination test has detected many old cases, often treated in the past, which would have been missed by less sensitive tests.

Syphilis and yaws have much in common. The causative agents, $T$ pallidum and $T$ pertenue, are morphologically indistinguishable. When freshly isolated they produce slightly different lesions in animals, but with repeated passage the behaviour of yaws strains approximates to that of $T$ pallidum. The serological response to infection with the two organisms is identical, and no serological test will differentiate yaws from syphilis. Yaws is contracted in childhood and spreads by direct contact, perhaps aided by insect vectors. The primary lesion at the site of inoculation is usually on the legs and is followed by exuberant secondary lesions, especially at mucocutaneous junctions and in moist areas. Eventually the disease becomes latent, but there may be late destructive lesions of the skin and bones. The cardiovascular and central nervous systems are spared, and congenital transmission is thought not to occur, though Englehart has questioned this. ${ }^{\text {? }}$

Faced with a symptomless patient born in an area where yaws has been endemic and whose serological tests for syphilis have been found positive, how can one tell whether the diagnosis should be syphilis or yaws? The problem is made more complicated by the possibility that both diseases may be present in one patient. Though yaws provides some immunity against syphilis, this may wane with time. Patients with a history or signs of old yaws may contract syphilis, ${ }^{8}$ and the birth of a child with frank congenital syphilis to a mother with old yaws has been reported. ${ }^{9}$ Nevertheless, a history of yaws is helpful, particularly if childhood was spent in a rural rather than an urban area, and presence of tissue paper scarring at the site of early lesions is suggestive. The patient's sexual partner should be examined and serological tests performed, and in women found to be seropositive tests should be carried out on their children as well. Serureactivity in these relatives favours a diagnosis of syphilis, as does the presence of cardiovascular or neurological signs or abnormalities in the cerebrospinal fluid. Though serological tests provide no absolute distinction, high titres in the reagin tests (VDRL $>1$ in 8 ) are rather more likely to be due to syphilis than to old yaws.

A diagnosis may be possible from consideration of these factors, but uncertainty often remains. Even though there may be a history of treatment for yaws, patients-and especially pregnant women-should be treated again with a course of 600000 units of procaine penicillin daily for 10 days. If they have old yaws, no harm will be done; if they have syphilis, this treatment should prevent the development of potential late manifestations of the more serious disease.

${ }^{1}$ Daly, J J, and Morton, R S, British fournal of Venereal Diseases, 1963, $39,98$.

2 Fry, L, and Rodin, P, British fournal of Venereal Diseases, 1966, 42, 28

${ }^{3}$ Lanigan-O'Keeffe, F M, Holmes, J G, and Hill, D, British fournal of Dermatology, 1967, 79, 325.

${ }^{4}$ Elste, G, British Fournal of Venereal Diseases, 1976, 52, 206.

${ }^{5}$ Fluker, J L, and Hewitt, A B, British fournal of Venereal Diseases, 1970, 46, 264.

${ }^{6}$ Chief Medical Officer of the Department of Health and Social Security, British fournal of Venereal Diseases, 1978, 54, 57.

${ }^{7}$ Engelhardt, H K, Fournal of Tropical Medicine and Hygiene, 1959, 62, 238

8 Dunlop, E M C, British fournal of Venereal Diseases, 1960, 36, 40.

9 Wilson, J, and Mauger, D G, New Zealand Medical fournal, 1973, 77, 384.

\section{Malnutrition and cancer}

American politicians are persuading their National Cancer Institute to spend more on studying the cause and treatment of malnutrition in patients with cancer. ${ }^{1}$ This campaign seems to be based more on claims by activist clinicians than on any breakthrough in basic research on the pathophysiology of cachexia. The first wave of published reports has been made up of largely anecdotal data; controlled trials and the fashionable backlash in opinion have yet to make an appearance.

What is being claimed by the enthusiasts is that nutritional support improves the clinical outcome of treatment-whether by resection of the tumour, by chemotherapy, or by radiotherapy. This idea is not new nor is the objection to it-that the tumour will be fed rather than the host. Conflicting evidence from experiments on rodents (where the tumour may 
account for $30 \%$ of the total body weight) have done little to answer the doubts. Patients with metastatic cancer rarely have a tumour burden of more than $10 \%$ of their weight, so that directly extrapolating the evidence from rodent to man is probably futile. Some studies have asserted that there was no acceleration of the tumour's growth after supplementary nutrition, but such assurances carry little conviction when based on negative observations during a relatively short period.

Copeland and his colleagues ${ }^{2}$ have described intravenous feeding to supplement chemotherapy in 58 malnourished patients with neoplastic disease. Without intravenous feeding these patients were considered either poor risks or unsuitable for any chemotherapy. Nutritional depletion was defined as a weight loss greater than $10 \%$ and a serum albumin concentration below $30 \mathrm{~g} / 1$. The $36 \%$ response rate suggested a correlation between nutritional state and the success of treatment; this is indeed plausible because chemotherapeutic drugs are metabolised according to the patient's nutritional level. ${ }^{3}$ Another report described 85 patients with cancer under the care of the nutrition service at St Joseph's Hospital, Toronto. ${ }^{4}$ They included patients referred before surgery and those with postoperative complications. Among the patients with resectable cancers who had nutritional support starting before operation no death or major complication occurred. In the postoperative group the death rate was $4.5 \%$ for cancer of the colon, but much higher for that of the oesophagus, pancreas, and bladder. Hill's nutrition group in Leeds ${ }^{5}$ has reported that giving intravenous feeding to patients undergoing proctocolectomy or rectal excision (for both benign and malignant disease) reduced postoperative complications and restored plasma protein concentrations to normal.

These few examples provide suggestive evidence that nourishment of patients may be beneficial during active treatment. While the exact value of these benefits remains uncertain, however, there is no doubt about the high costs of nutritional support in terms of manpower, use of beds, and money spent on elemental diets.

Furthermore, the enthusiasts seem unlikely to restrict themselves to this area of oncology: palliative nutritional supplements will also be tried in patients with advanced cancer on the grounds that some patients with cancer die in cachexia with no immediate cause of death visible at necropsypresumably these are "biochemical deaths." Is it possible to help them surmount this hurdle, or indeed reasonable to do so if they merely succumb to a more direct effect of their cancer at a later date? One or two months' longer survival as a semiinvalid is surely only a pyrrhic victory.

We still know very little about the pathophysiology of cachexia and can only guess how far along the pathway an individual patient has travelled. Protein-calorie deficiency is known to lead to a series of biochemical changes: the extent to which the serum albumin concentration falls below $30 \mathrm{~g} / 1$ is a guide to the probability of finding a whole host of disturbances in the concentrations of blood proteins, enzymes, trace elements, and vitamins. Each of these changes may be used as a marker of nutritional state reflecting disturbances of cellular function. Given sufficient time, the rates of change may be informative, but clinicians usually need rapid answers. This means finding out whether an array of biochemical measurements-in combination with factors such as loss of weight, anthropometric measurements, tumour site and load, and anaemia-can increase the accuracy of prediction that nourishment will improve the response to treatment. Apart from the concentration of serum albumin the use of transferrin, prealbumin, cholinesterase, and ribonuclease ${ }^{6}$ concentrations might be evaluated; other simple combinations have yet to be carefully assessed.

What we need, surely, is the pragmatic application of current knowledge to provide a broad base of data similar to that already published on malnourished children in the tropics. But we should have no delusions: in contrast to tropical malnutrition, the cachexia of cancer will need more than milk powder and vitamins to turn the tide.

\footnotetext{
1 Greenberg, D S, New England fournal of Medicine, 1978, 299, 207.

2 Copeland, E M, et al, American fournal of Surgery, 1975, 129, 167.

${ }^{3}$ Basu, T K, and Dickerson, J W T, Chemico-Biological Interactions, 1974, 8,193

4 Deitel, M, Vasic, V, and Alexander, M A, Cancer, 1978, 41, 2359.

5 Collins, J P, Oxby, C B, and Hill, G L, Lancet, 1978, 1, 788.

${ }^{6}$ Shenkin, A, Citrin, D L, and Rowan, R M, Clinica Chimica Acta, 1976, 72, 223.
}

\section{Drink and drown}

Shakespeare (as so often) said it supremely well and with double meaning. "I have very poor and unhappy brains for drinking," sighed Cassio 1 -and it can be as true for Adam's ale as for alcohol. Deliberately induced water intoxication ${ }^{2}$ is always dangerous and sometimes fatal. ${ }^{3}$ One danger is that the victim will inhale vomit while confused or having convulsions; the other is death from cerebral oedema with compression of the brain stem (especially if lumbar puncture is performed during the investigation).

Once hyponatraemia has been discovered and deliberate excessive water drinking is suspected the diagnosis is more likely to be made on the history than by examination or investigation. Neurotic traits and vague illnesses in the past can usually be discovered, sometimes with episodes of delusions, depression, agitation, or hysterical behaviour. Four out of five patients are women. ${ }^{4}$ Without such a history other causes are more likely, but a background of instability does not of course exclude an organic lesion such as an oat-cell carcinoma of the bronchus secreting antidiuretic vasopressinlike peptides. ${ }^{5}$ Reasons for drinking more water than is physiologically necessary are as varied as the personalities and psychopathies behind the syndrome: they range from the schizophrenic-determined to flush out the parasitic worm roaming his body ${ }^{6}$ - to the two psychopaths who, after reading a newspaper article on water addiction, grasped their opportunity for a weekend of free intoxication. ${ }^{7}$

The symptoms are due to intracellular overhydration. Water moves osmotically into cells which have become relatively hypertonic as the plasma osmolality falls. The onset of symptoms is determined by individual differences (which are poorly understood) in the level of hyponatraemia at which brain disturbance becomes apparent. Headache and vomiting are the first symptoms, the latter unfortunately being less protective than might be expected, because not all that is drunk is returned. Confusion, disorientation, and restlessness progress to convulsions and coma.

On logical grounds a urine osmolality substantially lower than that of the plasma should differentiate water drinksrs from other patients with hyponatraemia: indeed, their urine should be maximally dilute. Unfortunately, in practice the distinction is not so simple: either the disturbance of brain function initially associated with psychiatric illness or the onset of cerebral oedema itself may provoke the release of 